\title{
A novel approach to temporary stenting: degradable cardiovascular stents produced from corrodible metal-results 6-18 months after implantation into New Zealand white rabbits
}

\author{
M Peuster, P Wohlsein, M Brügmann, M Ehlerding, K Seidler, C Fink, H Brauer, \\ A Fischer, G Hausdorf
}

\begin{abstract}
Objective-To determine whether corrodible materials may be safely used as biodegradable cardiovascular implants.

Design-Corrodible iron stents ( $>99.8 \%$ iron) were produced from pure iron and laser cut with a stent design similar to a commercially available permanent stent (PUVA-AS16). A total of 16 NOR-I stents were implanted into the native descending aorta of 16 New Zealand white rabbits (mean luminal diameter at the implantation site $3.4 \mathrm{~mm}$, balloon diameter to vessel diameter ratio 1.13$)$.

Results-No thromboembolic complications and no adverse events occurred during the follow up of 6-18 months. All stents were patent at repeat angiography after $6(n=9), 12(n=5)$, and 18 months $(n=2)$ with no significant neointimal proliferation, no pronounced inflammatory response, and no systemic toxicity.

Conclusions-This initial in vivo experience suggests that degradable iron stents can be safely implanted without significant obstruction of the stented vessel caused by inflammation, neointimal proliferation, or thrombotic events.

(Heart 2001;86:563-569)
\end{abstract}

Keywords: congenital heart disease; corrosion; stents; biodegradation

In recent years, stents have assumed an increasingly important role in therapeutic catheterisation procedures for paediatric patients with congenital heart disease. ${ }^{1}$ In contrast to balloon dilatation, balloon expandable stents can maintain the patency of a stenotic vessel by preventing the intrinsic elastic recoil of the vessel wall. In paediatric patients, endovascular stents are most commonly implanted into peripheral pulmonary arterial stenoses or hypoplastic pulmonary arteries, ${ }^{2-7}$ but have also proved effective and safe for patients with systemic venous obstructive lesions ${ }^{189}$ and patients with (re)coarctation of the aorta. ${ }^{10-17}$

Despite the beneficial effects of endovascular stenting a major limitation of its use has been the creation of a fixed obstruction at the implantation site that evolves with the growth of the child. Redilatation of stents implanted into pulmonary arteries has been effectively and safely used to address this issue. ${ }^{6}{ }^{78-20}$ Depending on the stent design, the maximal stent diameter may often be less than the diameter required for the fully grown patient. As a result, fixed obstruction of the stented vessel occurs and may not be cured by transcatheter interventions. In those patients, surgery is often required to remove the stent or to cut the stent longitudinally and patch the vessel to provide further enlargement. The use of degradable stents that can temporarily withstand radial forces of the vessel before losing their mechanical stability may solve this problem.

In the search for a biodegradable stent, various polymers (poly-D,L-lactide/glycolite copolymer, polycaprolactone, polyhydroxybutyrate-hydroxyvalerate and polyorthoester, low molecular weight poly-Llactide) have been evaluated in a porcine coronary model. ${ }^{21}{ }^{22}$ All polymers were associated either with a significant inflammatory response and neointimal proliferation or with complete thrombotic occlusion of the vessel. In contrast to these findings, recent reports suggest that high molecular weight poly-Llactic acid is biocompatible in a porcine coronary arterial model ${ }^{2123}$ and encouraging results were reported six months after implantation in to human coronary arteries. ${ }^{24}$

Our study was performed to test whether corrodible iron stents ( $>99.8 \%$ iron) may safely be used for endovascular stenting of the descending aorta with minimal inflammatory response and low thrombogenicity. Therefore, patency rates and local and systemic toxicity were assessed 6-18 months after implantation of degradable iron stents (NOR-I, Devon Medical, Hamburg, Germany) into the descending aorta of New Zealand white rabbits.

\section{Methods}

IN VITRO DEGRADATION RATE OF CORRODIBLE STENT MATERIAL

To evaluate degradation rates ex vivo in a standard setting, iron probes with a diameter of $26 \mathrm{~mm}$ and a thickness of $0.91 \mathrm{~mm}(99.8 \%$ iron; Goodfellow, Cambridge, UK) were placed in an electrolyte solution (volume $1000 \mathrm{ml}$, Ringer solution, Fresenius AG, Bad Homburg, Germany) and incubated under continuous stirring at a constant temperature 


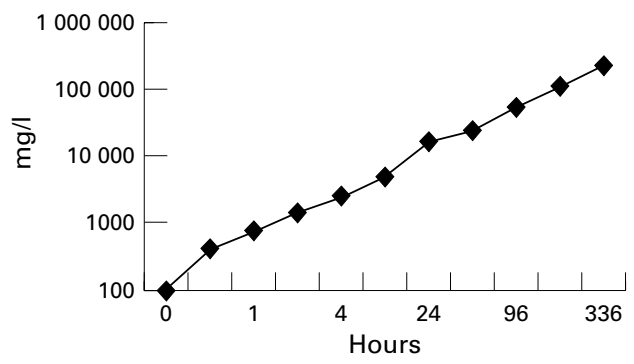

Figure 1 Accumulation of iron in the electrolyte in relation to time.

of $37^{\circ} \mathrm{C}$ for two weeks. After short time intervals (fig 1) $40 \mathrm{ml}$ samples were taken from the electrolyte solution and the total volume was restocked to $1000 \mathrm{ml}$. Electrolyte samples were examined by inductive coupled plasma atomic emission spectroscopy to determine the iron concentration. Loss of substance was calculated in relation to the surface $\left(\Delta \mathrm{m}_{\mathrm{A}}\right)$ by the difference of the weight of the sample before incubation $\left(\mathrm{G}_{0}\right)$ and the weight at the time the probe was removed from the electrolyte $\left(\mathrm{G}_{\mathrm{t}}\right)$ : $\Delta \mathrm{m}_{\mathrm{A}}=\mathrm{G}_{\mathrm{t}}-\mathrm{G}_{0}$. The loss of mass was also calculated as a function of time, where $\mathrm{v}=\Delta \mathrm{m}_{\mathrm{A}} / \mathrm{t}$.

\section{ANIMALS}

The study was conducted with the approval of the local governmental authorities and adhered to the Guide for the care and use of laboratory animals (NIH publication 85-23, 1985). Sixteen fully grown female New Zealand white rabbits (mean weight $4.04 \mathrm{~kg}$, range 3.2 $5.1 \mathrm{~kg}$ ) were purchased from Charles River (Kisslegg, Germany) and fed a standard diet without lipid or cholesterol supplementation throughout the study.

STENTS

The degradable stents (NOR-I stents) were laser cut from commercially available iron tubes (99.8\% iron, Goodfellow). The stents were cut in a nitrogen atmosphere to prevent corrosion of the metal. The degradable stents were produced with a slotted tube stent design similar to a commercially available permanent coronary stent with an inflated stent diameter of 3-6 $\mathrm{mm}$ and a length of $16 \mathrm{~mm}$ (PUVAAS16 stent, Devon). After laser cutting, the NOR-I stents were polished to achieve a strut thickness of $100-120 \mu \mathrm{m}$. A NOR-I stent weighs $0.041 \mathrm{~g}$. In airtight vials filled with nitrogen to prevent corrosion, the stents were sterilised with $\gamma$ rays and stored before implantation. The crimped stent opened at a balloon inflation pressure of $3.5 \mathrm{~atm}$. Recoil of the stent was $2.2 \%$ as assessed by previously described methods. ${ }^{25}$

\section{PROCEDURE}

After premedication with intramuscular ketamine $(10 \mathrm{mg} / \mathrm{kg})$ and intramuscular midazolam $(1 \mathrm{mg} / \mathrm{kg})$, pentobarbitone $(10 \mathrm{mg} / \mathrm{kg})$ was administered intravenously before the rabbits were intubated. Anaesthesia was induced and maintained by inhalation of $1-3 \%$ isoflurane. Antibiotic prophylaxis was administered intramuscularly. Continuous electrocardiography and end tidal carbon dioxide were monitored throughout the procedure. The right femoral artery was surgically exposed and a 4 French sheath introduced over a 0.018 inch guidewire. Heparin (100 IU/kg) was administered as a bolus. Quantitative angiography of the descending aorta was performed to determine the luminal diameter of the descending aorta at the site of the implantation (4 French Berman angiography catheter, Arrow, Reading, Pennsylvania, USA). Balloon catheters with a balloon diameter of 3.5 to $4 \mathrm{~mm}$ (Savyy, Cordis, Miami, Florida, USA) were chosen to achieve a balloon to vessel ratio from 1.1 to 1.2 (mean 1.13). The degradable iron stent was manually crimped to the balloon catheter. Under fluoroscopic control the stent was introduced and positioned at the predetermined implantation site. Placing the stent across the orifice of major branches of the descending aorta was avoided. The stents were implanted with 10-12 atm for 10 seconds. After 10 minutes angiography was again performed to confirm vessel patency and to exclude filling defects caused by thrombi, vessel wall dissection, or inadequate stent deployment. After removal of the catheter and sheath, the femoral artery was ligated and the incision of the skin was closed with interrupted sutures. The animals were extubated and returned to a postoperative recovery area. Dipyridamole and aspirin were added to the drinking water to result in a dosage of $2 \mathrm{mg} / \mathrm{kg} / \mathrm{day}$ of each substance as calculated for an assumed daily
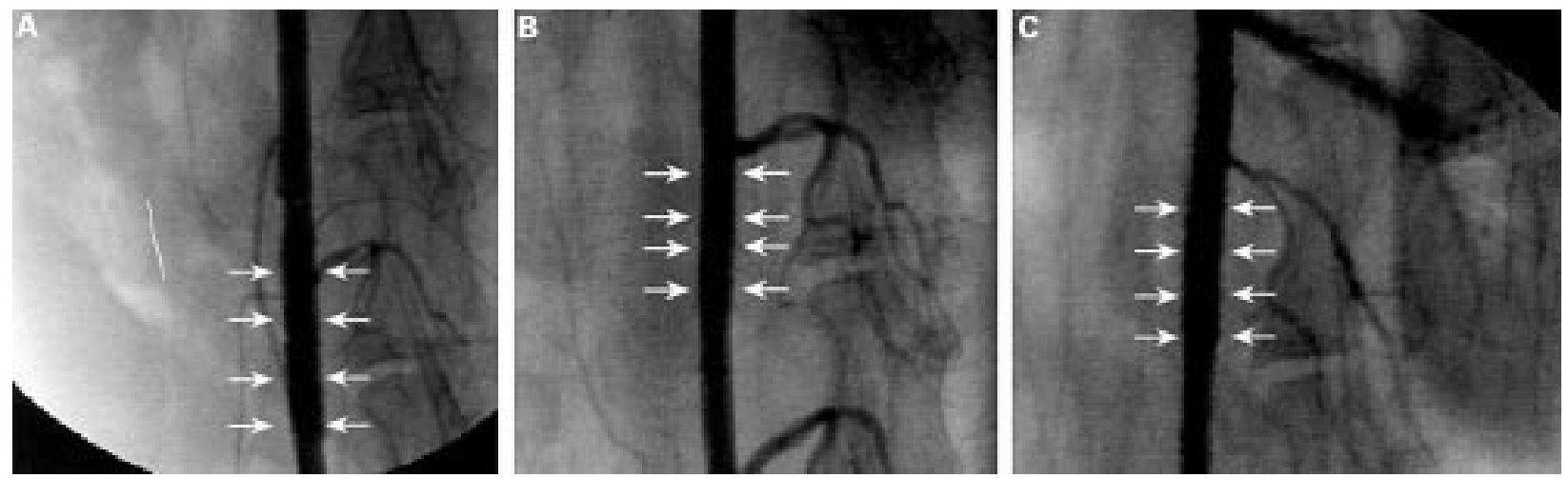

Figure 2 Lateral angiography of the stented descending aorta (A) six months, (B) 12 months, and (C) 18 months after implantation. There is complete patency of the vessel. (Arrows indicate stent implantation site.) 
Table 2 Data of quantitative angiography at follow up

\begin{tabular}{llllllllll}
\hline Group & $\begin{array}{l}\text { APDAO } \\
(\mathrm{mm})\end{array}$ & $\begin{array}{l}\text { LATDAO } \\
(\mathrm{mm})\end{array}$ & $\begin{array}{l}\text { LADAO } \\
\left(\mathrm{mm}^{2}\right)\end{array}$ & $\begin{array}{l}\text { Mean APST } \\
(\mathrm{mm})\end{array}$ & $\begin{array}{l}\text { Mean LATST } \\
(\mathrm{mm})\end{array}$ & $\begin{array}{l}\text { LAST } \\
\left(\mathrm{mm}^{2}\right)\end{array}$ & $\begin{array}{l}\text { CLA } \\
(\%)\end{array}$ & $\begin{array}{l}\text { CAPLD } \\
(\%)\end{array}$ & $\begin{array}{l}\text { CLATLD } \\
(\%)\end{array}$ \\
\hline I & 3.34 & 3.71 & 9.76 & 3.44 & 3.40 & 9.24 & 95 & 103 & 92 \\
II & 2.97 & 3.57 & 8.39 & 3.12 & 3.29 & 8.13 & 99 & 106 & 93 \\
III & 3.34 & 3.04 & 7.98 & 3.25 & 3.23 & 8.24 & 103 & 97 & 106 \\
\hline
\end{tabular}

APDAO, mean anterior-posterior diameter of the descending aorta $1 \mathrm{~cm}$ proximal to the stent; CAPLD, change of anteroposterior luminal diameter ; CLA, change of luminal area; CLATLD, change of lateral luminal diameter; LADAO, mean luminal area of the descending aorta $1 \mathrm{~cm}$ proximal to the stent; LAST, luminal area of the stent; LATDAO, mean lateral diameter of the descending aorta $1 \mathrm{~cm}$ proximal to the stent; Mean APST $_{1-3}$, mean anteroposterior diameter of the stent lumen (measured at $3 \mathrm{~mm}$, $9 \mathrm{~mm}$, and $15 \mathrm{~mm}$ of the $18 \mathrm{~mm}$ stent); Mean LATST ${ }_{1-3}$, mean lateral diameter of the stent lumen (measured at $3 \mathrm{~mm}, 9 \mathrm{~mm}$, and $15 \mathrm{~mm}$ of the $18 \mathrm{~mm}$ stent)

intake of $30 \mathrm{ml}$ water $/ \mathrm{kg}$ body weight. Antiplatelet treatment was discontinued after three months.

FOLLOW UP

The clinical condition of the animals was followed up and documented throughout the study. Follow up angiographies were performed after $6(n=9), 12(n=5)$, and 18 months $(n=2)$ using a contralateral femoral arterial cut down.

\section{Quantitative angiography}

The stents were crossed with a 4 French Berman angiography catheter and quantitative anteroposterior and lateral angiography was performed with the catheter advanced close to the stents. To determine the change of luminal area (loss of luminal area caused by neointimal proliferation or gain of luminal area caused by overexpansion of the stent) at the junction of the proximal descending aorta to the stented descending aorta, the following measurements were obtained. The anteroposterior (APDAO) and lateral (LATDAO) diameters of the descending aorta $1 \mathrm{~cm}$ proximal to the stent were determined, and the anteroposterior (APST) and lateral (LATST) luminal diameters were measured at three sites of the stented vessel (stent length $18 \mathrm{~mm}$ : diameter 1 at $3 \mathrm{~mm}$, diameter 2 at $9 \mathrm{~mm}$, and diameter 3 at $15 \mathrm{~mm}$ ). The luminal area of the unstented descending aorta (LADAO) was calculated as follows:

LADAO $\left(\mathrm{mm}^{2}\right)=\mathrm{APDAO} / 2 \times \mathrm{LATDAO} / 2 \times \pi$

The luminal area of the stented descending aorta (LAST) was calculated using the mean anteroposterior diameter of the stented segment and the mean lateral diameter of the stented segment:

LAST $\left(\mathrm{mm}^{2}\right)=$ mean $\left(\operatorname{APST}_{1-3}\right) / 2 \times$ mean $\left(\operatorname{LATST}_{1-3}\right) / 2 \times \pi$

Change of luminal area (\%) was calculated as LAST/LADAO.

Change (\%) of anteroposterior (mean $\left(\mathrm{APST}_{1-3}\right) / \mathrm{APDAO}$ ) and lateral (mean $\left(\text { LATST }_{1-3}\right)_{\text {LATDAO) luminal diameter were }}$ calculated.

MORPHOLOGICAL INVESTIGATION

After angiography the animals were sacrificed by an intravenous injection of a lethal dose of pentobarbital. Immediately after death the infradiaphragmatic descending aorta was exposed and the stented segment was identified. The aortic segment was removed with at least $0.5 \mathrm{~cm}$ unstented aorta proximally and distally to the stent. The segments were intensely rinsed with isotonic sodium chloride to remove clotted blood and then placed in 3.5\% neutral buffered formalin and kept for histopathological investigation. Additionally, tissue specimens of liver, kidney, spleen, heart, lung, and separately dissected para-aortic adipose tissue were obtained and fixed in $3.5 \%$ neutral buffered formalin.

The stents were cut longitudinally and the lumen of the stented vessel was evaluated for signs of adherent thrombi or overt neointimal obstruction of the vessel. After careful dissection of the stent struts, the stents were embedded in paraffin wax according to a standard laboratory protocol. Tissue sections of $3-5 \mu \mathrm{m}$ were produced of the stented aorta and stained with haematoxylin and eosin, periodic acidSchiff reagent, Azan stain, elastic van Gieson's stain, and Turnbull's blue iron stain. One specimen of each study group was viewed under a scanning electron microscope after critical point drying and gold sputtering to assess endothelialisation of the stent struts.

\section{Results}

DEGRADATION RATE IN VITRO

Figure 1 shows the accumulation of iron in the electrolyte solution in relation to time. The degradation rate of iron was calculated to be $\mathrm{v}=1697 \mathrm{~g} /\left(\mathrm{m}^{2} \times \mathrm{h}\right)$.

STENT IMPLANTATION

The degradable iron stents were implanted in the predetermined segment of the descending aorta in 16 rabbits without complications (table 1). The mean luminal diameter of the infrarenal descending aorta at the implantation site was $3.4 \mathrm{~mm}$ (range $3.2-3.7 \mathrm{~mm}$ ). Coronary angioplasty catheters with a balloon diameter of 3.5-4.0 mm were chosen to achieve a

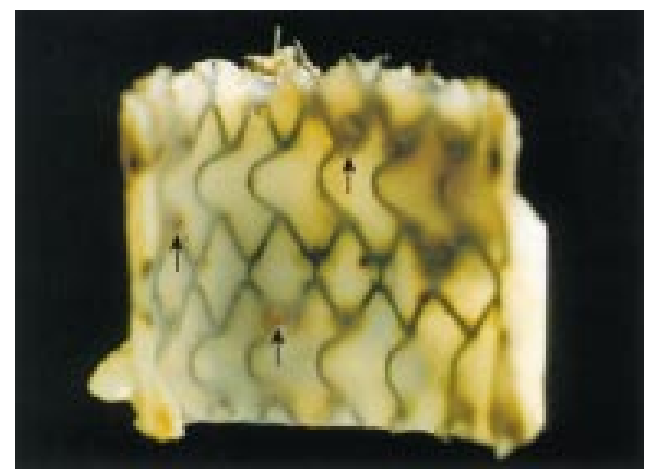

Figure 3 Rabbit aorta with degradable iron stent 12 months after implantation with numerous pinpoint, slightly raised plaques consisting of corroded stent material (arrows). 
Table 1 Description of the study groups

\begin{tabular}{lllllll}
\hline Group & $\begin{array}{l}\text { Follow up } \\
\text { (months) }\end{array}$ & $N$ & $\begin{array}{l}\text { Mean balloon } \\
\text { diameter } \\
(\mathrm{mm})\end{array}$ & $\begin{array}{l}\text { Mean diameter of } \\
\text { the descending } \\
\text { aorta }(\mathrm{mm})\end{array}$ & $\begin{array}{l}\text { Mean balloon } \\
\text { to vessel } \\
\text { diameter ratio }\end{array}$ & $\begin{array}{l}\text { Mean body } \\
\text { weight at } \\
\text { implantation (kg) }\end{array}$ \\
\hline I & 6 & 9 & 3.9 & 3.4 & 1.15 & 4.17 \\
II & 12 & 5 & 3.7 & 3.3 & 1.12 & 4.1 \\
III & 18 & 2 & 3.75 & 3.3 & 1.14 & 3.45 \\
\hline
\end{tabular}

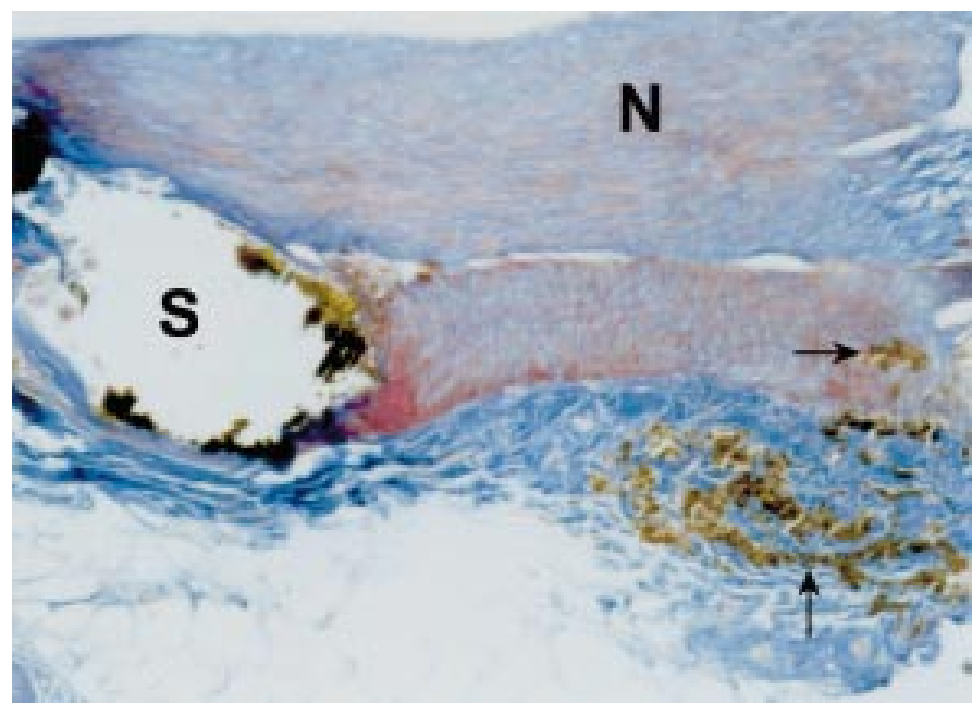

Figure 4 Rabbit aorta with degradable iron stent (S) six months after implantation; most of the stent struts are artificially lost and remnants of the iron are visible as plaques of brownish pigment. The stent strut is completely covered by neointima (N). Adjacent to the stent strut there is accumulation of iron laden macrophages within the media and adventitia (arrow). Azan stain, original magnification $\times 10$.

mean balloon diameter to APDAO ratio of 1.13 (range 1.09-1.18). Angiography after the implantation of the stents showed that the descending aorta was patent in all animals with no signs of intraluminal defects or dissection of the vessel wall. Redilatation was not necessary in any of the rabbits. After recovery from anaesthesia, there were no signs of impaired perfusion of the extremity where the femoral artery was ligated.

FOLLOW UP ANGIOGRAPHY

There were no deaths during the study period and no signs of clinical pathology in any of the rabbits. The animals were gaining weight adequately. Angiography 6, 12, and 18 months after the implantation showed complete patency of the descending aorta in all rabbits with no obstruction or thrombosis at the implantation site of the degradable iron stent (fig 2). Vessel patency rate was $100 \%$. Compared with the native descending aorta, the loss of APST or luminal area was less then $10 \%$ (table $2^{2}$ ).

PATHOMORPHOLOGICAL INVESTIGATION

Macroscopic evaluation of the stented vessel specimen found a continuously smooth and intact endothelial surface without evidence of thrombus formations or significant narrowing of the stented artery in any of the animals. The surface of the cut stent struts was brown to black. The vascular wall adjacent to the stent also had a brownish tinge (fig 3). At the junctions of the stent struts, there was pronounced accumulation of degradation products, which led to a slight elevation of the vessel wall and a focal brownish discolouration of

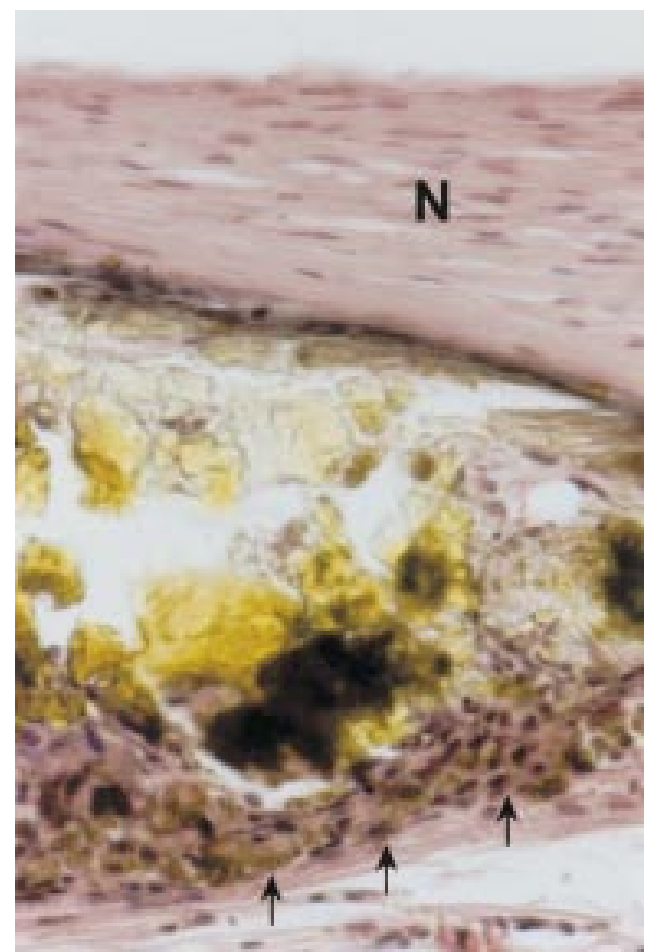

Figure 5 Rabbit aorta with degradable iron stent 18 months after implantation. A stent strut is covered by neointima $(N)$; along the adventitial side there is moderate infiltration of macrophages (arrows). Haematoxylin and eosin stain, original magnification $\times 40$.

the intima. On cut surfaces the struts appeared to be brittle. No differences were noted macroscopically between the two groups of stent thickness. The organs and para-aortic fatty tissue appeared without gross lesions.

Histologically, degradation of the iron struts was evident by loss of distinct border lines. The struts appeared as coarse granular brownish material located in the intima and predominantly in the media of the aorta (fig 4 ). Independently of the strut thickness and the time of follow up, the inflammatory reaction was intra- and interindividually variable. Accumulation of iron laden macrophages and multinucleated giant cells ranged from a sparse isolated localisation to accumulation in clusters (fig 5). Often, macrophages with brownish pigments were found within the adjacent media or the fibrous adventitia of the aorta, sometimes close to lymphatic capillaries (fig 6). In relation to the grossly observed slightly raised plaques, focally extensive areas of coarse granular brownish pigment with an elevated neointimal surface were observed. In one case six months after implantation of a stent with a strut thickness of $100 \mu \mathrm{m}$ within this focus, a vascularised granulation tissue with mild perifocal inflammatory reaction was present (fig 7). At the level of the stent struts the internal elastic membrane was regularly destroyed (fig 8). Consistently the media was severely indented and compressed to at least half its regular thickness. In many places the media was almost or totally destroyed at the implantation site of the stent strut. Along the surface, the struts were incorporated within a 
neointima consisting of fibroblastoid to fibrous cells with fibrillar extracellular matrix, which was in continuity with the adjacent, only

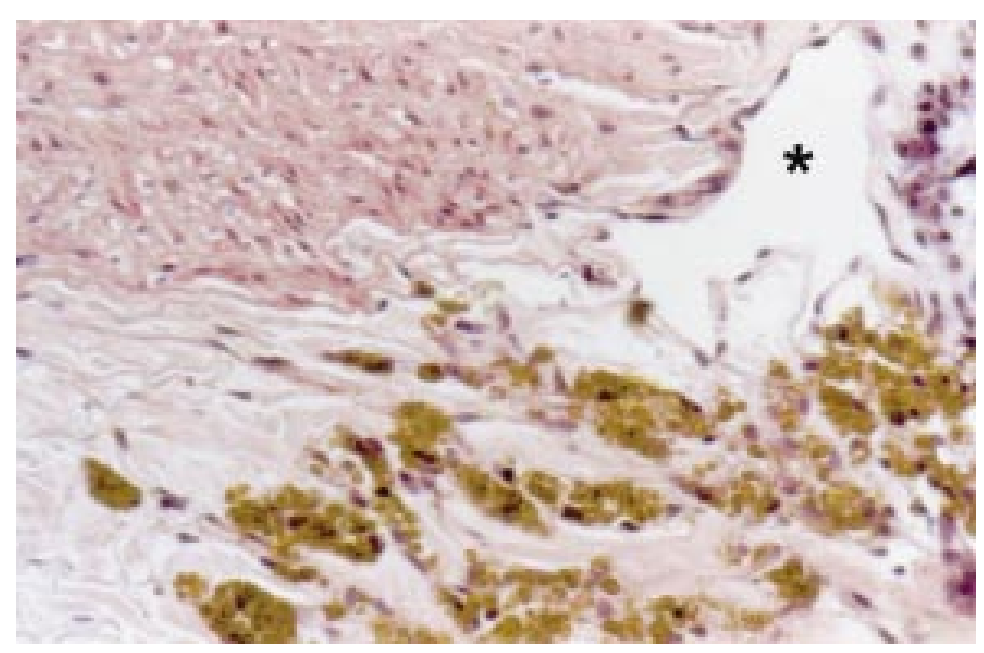

Figure 6 Rabbit aorta 18 months after iron stent implantation. Numerous siderophages are seen in the adventitia adjacent to a lymphatic capillary ( $\left.{ }^{\star}\right)$. Haematoxylin and eosin stain, original magnification $\times 40$.

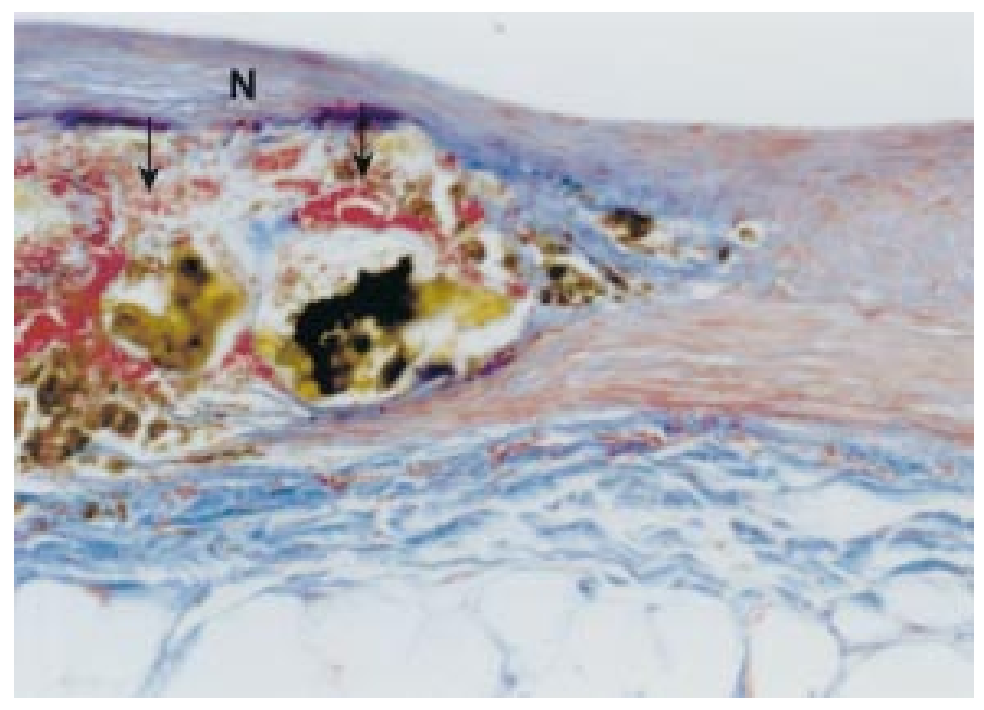

Figure 7 Rabbit aorta with iron stent 12 months after implantation. A stent strut is covered by neointima $(N)$ and adjacent to the advanced degraded iron strut there is vascularisation with some capillaries (arrows). Azan stain, original magnification $\times 20$.

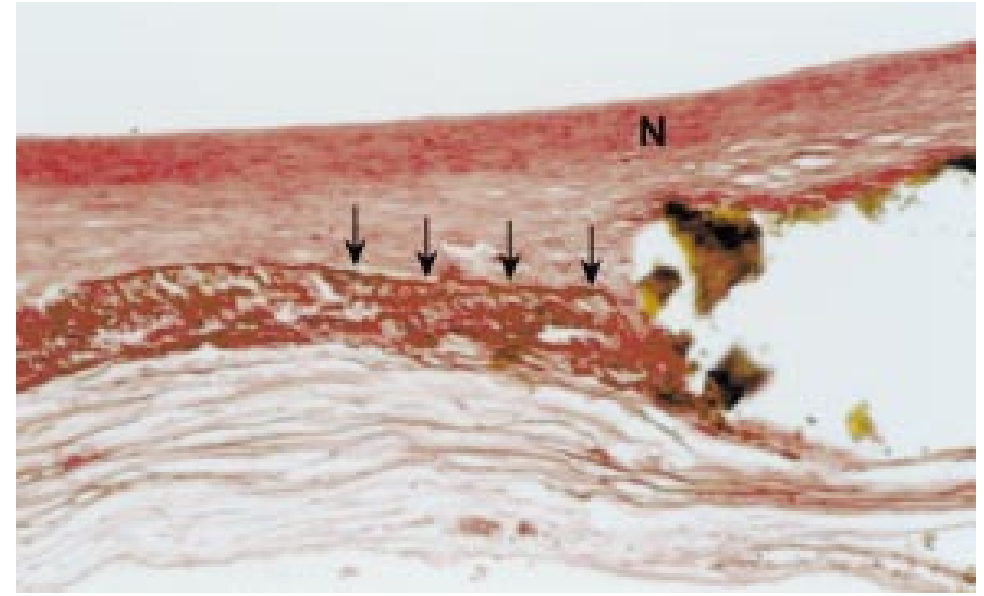

Figure 8 Rabbit aorta with degradable iron stent 18 months after implantation showing a stent strut covered by neointima $(N)$; media and internal elastic membrane destroyed adjacent to the stent strut. Elastic stain; original magnification $\times 20$. slightly thickened intima. The surface was covered with endothelial cells without evidence of thrombus formations. Adjacent to the struts gradually variable amounts of intercellular fine to coarse granular brownish material was present, which stained positive with the Turnbull blue iron stain.

The spleens of all the rabbits had no significant haemosiderosis. In the kidneys of some animals focally mild interstitial lymphocytic infiltrations or mild pigment accumulations in tubular cells were observed. The lungs and hearts were without significant findings and without signs of iron overload. In the paraaortic fibrous and fatty tissue focally mild to moderate infiltrations or pigment laden macrophages were present adjacent to the stent struts.

Scanning electron microscopy showed continuous endothelial coverage of the luminal surface along the stented abdominal aorta (fig 9).

\section{Discussion}

Most medical implants are only needed for a limited period of time to support healing temporarily. It was speculated that coronary stents have no clear function six months after implantation. ${ }^{26}$ After that initial period, permanent stents may interfere with normal vessel functions, leading to adaptive changes or abnormal reactions of the tissue surrounding the medical implant. ${ }^{27}{ }^{28} \mathrm{~A}$ particular problem with regard to permanent implants is the increasing size of implanted cardiovascular tissue in a growing person, resulting in disproportions of the implant and tissue or organ size. Furthermore, permanent implants deployed in a child have to be designed for a time of up to 80 years.

Our study is the first to show the feasibility and safety of degrading stents produced from corrodible metal. All stents were successfully deployed without periprocedural complications. Despite a less aggressive antithrombotic

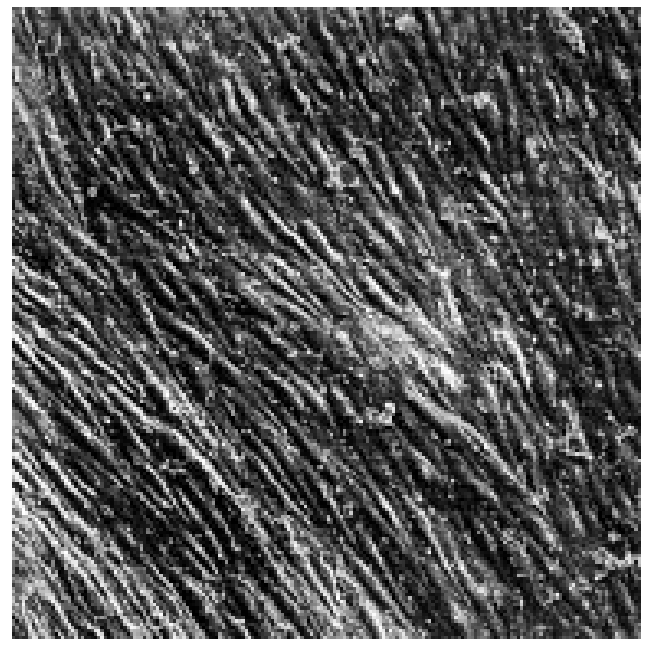

Figure 9 New Zealand white rabbit 12 months after implantation; scanning electron microscopic view of the aortic neointima continuously covered by confluent endothelial cells. Note that coagulation of plasma components and thrombocytes on the surface was caused by inadequate preparation of the specimen. Original magnification $\times 330$. 
regimen using oral aspirin and dipyridamole for three months instead of ticlopidine, clopidogrel, or abciximab, no stent thrombosis was observed. There was neither pronounced neointimal proliferation nor significant inflammatory response of the stented vessel. All animals survived the follow up period without any adverse clinical events. Histopathological and macroscopic evaluation of the animals' organs excluded organ accumulation of the degradation products and systemic toxicity. Despite destruction of the internal elastic membrane and accumulation of degradation products with significant alteration of the media, none of the animals showed aneurysmatic changes of the descending aorta. There was no pronounced cell proliferation. Although the study group of 16 animals was small, the results of this study are encouraging.

A major advantage of this concept of using a corrodible iron stent as a degradable medical implant is the well known interaction of iron with the organism. Iron is an essential component of a variety of enzymes. Transport absorption and storage mechanisms for iron are well known and make iron or iron based alloys favourable candidates for use as a biodegradable implant material, especially when used in the growing child. ${ }^{29}$ The advantages of iron as a material for use as a degradable implant are obvious. The amount of pure iron implanted with a single iron $(99.8 \%)$ stent (41 mg) equals the monthly oral intake of iron: it is less than the recommended daily dose of intravenous iron dextran ${ }^{30} 31$ and much less than the amount of iron transfused with one unit of blood (200-250 mg). ${ }^{29}$ Therefore, the biocompatibility of iron can be assumed to be good. Mechanical properties of iron are comparable with those of available metal alloys for permanent cardiovascular implants.

The implantation technique that has been used for the implantation of biodegradable poly-L-lactide stents ${ }^{24}$ is complicated. Heated dye at $80^{\circ} \mathrm{C}$ has to be used for stent delivery balloon inflation. With the use of poly-L-lactide stents, uncontrolled expansion of the poly-Llactide stent was observed $\geqslant 3$ months after the implantation. ${ }^{32}$ In contrast to these findings, the deployment technique and mechanical characteristics of the NOR-I stent are not different from those of available stents. Expansion characteristics and recoil of NOR-I stents are clearly defined.

\section{DEGRADATION RATE}

A major limitation of this and other ${ }^{24}{ }^{32}$ in vivo studies on biodegradable cardiovascular implants is that in vivo degradation rates cannot be assessed. Since it is generally accepted that stent dissolution must not occur before six months to prevent mechanical device failure or fragment embolisation of the vessel, we aimed to achieve a relatively slow degradation rate for this initial in vivo study. Since degradation rates in vivo were found to be slower than expected in vitro, future research has to focus on the kinetics of in vivo corrosion and its modification either by using an iron based alloy or by modifying the surface and structure of the stent to achieve a faster degradation.

CONCLUSION

NOR-I stents have a low thrombogenicity and cause only mild inflammatory response of the stented vessel without pronounced neointimal hyperplasia. They lack local or systemic toxicity. Further research on accelerating the degradation of NOR-I stents is warranted.

We would like to thank Jörg Meyer and Frank Skrzipczyk, Devon Medical, Hamburg, Germany, for their support with the production of the stents.

1 Allen HD, Beekman RH III, Garson A Jr, et al. Pediatric therapeutic cardiac catheterization: a statement for healthcare professionals from the Council on Cardiovascular Disease in the Young, American Heart Association. Circulation 1998;97:609-25.

2 Benson LN, Hamilton F, Dasmahapatra H, et al. Percutaneous implantation of a balloon-expandable endoprosthesis for pulmonary artery stenosis: an experimental study. $\mathcal{f} \mathrm{Am}$ for pulmonary artery stenosis:

3 Benson LN, Nykanen D, Freedom RM. Endovascular stents in pediatric cardiovascular medicine. F Interv Cardiol 1995; 8:767-75.

4 Mendelsohn AM, Bove EL, Lupinetti FM, et al. Intraoperative and percutaneous stenting of congenital pulmonary artery and vein stenosis. Circulation 1993;88:II210-7.

5 O'Laughlin MP, Perry SB, Lock JE, et al. Use of endovascular stents in congenital heart disease. Circulation 1991;83: 1923-39.

6 O'Laughlin MP, Slack MC, Grifka RG, et al. Implantation and intermediate-term follow-up of stents in congenital heart disease. Circulation 1993;88:605-14.

7 Shaffer KM, Mullins CE, Grifka RG, et al. Intravascular stents in congenital heart disease: short- and long-term results from a large single-center experience. $\mathcal{f} \mathrm{Am}$ Coll Cardiol 1998;31:661-7.

8 Chatelain P, Meier B, Friedli B. Stenting of superior vena cava and inferior vena cava for symptomatic narrowing cava and inferior vena cava for symptomatic narrowing
after repeated atrial surgery for D-transposition of the great after repeated atrial surgery for D-t.

9 Ward CJ, Mullins CE, Nihill MR, et al. Use of intravascular stents in systemic venous and systemic venous baffle obstructions. Short-term follow-up results. Circulation 1995;91:2948-54.

10 Ebeid MR, Prieto LR, Latson LA. Use of balloonexpandable stents for coarctation of the aorta: initial results and intermediate-term follow-up. $\mathcal{f} \mathrm{Am}$ Coll Cardiol 1997;30:1847-52.

11 Magee AG, Brzezinska-Rajszys G, et al. Stent implantation for aortic coarctation and recoarctation. Heart 1999;82: $600-6$.

12 Redington AN, Hayes AM, Ho SY. Transcatheter stent implantation to treat aortic coarctation in infancy. Br Heart f 1993;69:80-2.

13 Redington AN, Weil J, Somerville J. Self expanding stents in congenital heart disease. Br Heart f 1994;72:378-83.

14 Rosenthal E, Qureshi SA, Tynan M. Stent implantation for aortic recoarctation. Am Heart f 1995;129:1220-1

15 Suarez de Lezo J, Pan M, Romero M, et al. Immediate and follow-up findings after stent treatment for severe coarctation of aorta. Am f Cardiol 1999;83:400-6.

16 Suarez de Lezo J, Pan M, Romero M, et al. Balloonexpandable stent repair of severe coarctation of aorta. $\mathrm{Am}$ Heart f 1995;129:1002-8.

17 Thanopoulos BD, Hadjinikolaou L, Konstadopoulou GN, et al. Stent treatment for coarctation of the aorta: intermediate term follow up and technical considerations. Heart 2000;84:65-70.

18 Fogelman R, Nykanen D, Smallhorn JF, et al. Endovascular stents in the pulmonary circulation: clinical impact on management and medium-term follow-up. Circulation 1995;92:881-5.

19 Ing FF, Grifka RG, Nihill MR, et al. Repeat dilation of intravascular stents in congenital heart defects. Circulation 1995;92:893-7.

20 Morrow WR, Palmaz JC, Tio FO, et al. Re-expansion of balloon-expandable stents after growth. $\mathcal{F}$ Am Coll Cardiol 1993;22:2007-13.

21 Lincoff AM, Furst JG, Ellis SG, et al. Sustained local delivery of dexamethasone by a novel intravascular eluting stent to prevent restenosis in the porcine coronary injury model. 7 Am Coll Cardiol 1997;29:808-16.

22 van der Giessen WJ, Lincoff AM, Schwartz RS, et al. Marked inflammatory sequelae to implantation of biodegradable and nonbiodegradable polymers in porcine coronary arteries. Circulation 1996;94:1690-7.

23 Yamawaki T, Shimokawa H, Kozai T, et al. Intramural delivery of a specific tyrosine kinase inhibitor with biodegradable stent suppresses the restenotic changes of the coronary able stent suppresses the restenotic changes of the coronary
artery in pigs in vivo. $7 \mathrm{Am}$ Coll Cardiol 1998;32:780-6.

24 Tamai H, Igaki K, Kyo E, et al. Initial and 6-month results of biodegradable poly-1-lactic acid coronary stents in humans. Circulation 2000;102:399-404. 
$25 \mathrm{Mahr}$ P, Fischer A, Brauer H, et al. Biophysical study of coronary stents: which factors influence the dilatation and Kardiol 2000;89:513-21.

26 Colombo A, Karvouni E. Biodegradable stents: "fulfilling the mission and stepping away". Circulation 2000;102:371-3.

27 Hoffmann R, Mintz GS, Popma JJ, et al. Chronic arterial responses to stent implantation: a serial intravascular ultrasound analysis of Palmaz-Schatz stents in native coronary arteries. F Am Coll Cardiol 1996;28:1134-9.

28 van Beusekom HM, Whelan DM, Hofma $\mathrm{SH}$, et al. Long-term endothelial dysfunction is more pronounced after stenting than after balloon angioplasty in porcine coronary arteries. F Am Coll Cardiol 1998;32:1109-17.
29 Andrews NC. Disorders of iron metabolism. $N$ Engl f Med 1999;341:1986-95.

30 Auerbach $\mathrm{M}$, Winchester J, Wahab A, et al. A randomized trial of three iron dextran infusion methods for anemia in EPO-treated dialysis patients. Am F Kidney Dis 1998;31: $81-6$.

31 Auerbach $\mathrm{M}$, Witt D, Toler W, et al. Clinical use of the total dose intravenous infusion of iron dextran. 7 Lab Clin Med 1988;111:566-70.

32 Tamai H, Igaki $\mathrm{K}$, Tsuji $\mathrm{T}$, et al. A biodegradable poly-l-lactic acid coronary stent in porcine coronary artery [abstract]. F Interv Cardiol 1999;12:443-450.

\section{Electronic pages}

\section{eHEART: www.heartjnl.com}

The following electronic only articles are published in conjunction with this issue of Heart (see also p 532).

\section{Long term follow up of long QT syndrome treated by overdrive pacing \\ $B$ Campanelli, $\mathcal{F}-M$ Chaudron}

Long term follow up of a patient with idiopathic long QT syndrome is described. A 5 year old girl was admitted with attacks of unconsciousness. Epilepsy was diagnosed and the patient was treated with anticonvulsants. During other episodes, ECG study showed torsades de pointes. The patient was treated with $\beta$ blockers, stellectomy without success, and later with overdrive pacing. The young woman is now 43 years old and in good health. It is suggested that early overdrive pacing be implanted in young people with symptomatic long QT syndrome.

(Heart 2001;86:e14) www.heartjnl.com/cgi/content/full/ $86 / 5 / \mathrm{e} 14$

\section{Coronary stent deployment in situs inversus \\ N Robinson, $P$ Golledge, A Timmis}

Situs inversus with dextrocardia occurs in approximately one in 10000 patients. Successful stent deployment for the treatment of unstable angina and situs inversus is presented. Three technical challenges associated with the procedure are highlighted. Firstly, the successful choice of diagnostic and interventional catheters is based on an understanding of the orientation of the aortic arch. With a right sided aorta Judkins catheters should be successful.
Secondly, image reversal is not necessarily required for image interpretation. Thirdly, successful coronary engagement with catheters requires rotation in a direction opposite to that normally used.

(Heart 2001;86:e15) www.heartjnl.com/cgi/content/full/ $86 / 5 /$ e 15

\section{Fulminant thrombosis of mechanical mitral valve prosthesis \\ $M$ Zielinska, N F Haegele, C Firschke}

In patients with prosthetic heart valves non-cardiac surgery may require temporary discontinuation of oral anticoagulation. Although the risk of valve related thromboembolic complications may generally be only slightly increased during the short perioperative period, in the presence of certain risk factors, replacement of oral anticoagulation with heparin is recommended. In the presented patient, unusually fulminant and finally fatal thrombosis of a mechanical mitral valve prosthesis developed within only 48 hours after non-cardiac surgery despite heparin treatment. The thrombosis was triggered by clinical conditions favouring a hypercoagulable state. This report dramatically shows that despite improvements in prosthetic heart valve design and in the management of anticoagulation, thrombosis remains one of the most dangerous complications after valve replacement with a mechanical prosthesis.

(Heart 2001;86:e16) www.heartinl.com/cgi/content/full/ $86 / 5 / \mathrm{e} 16$ 